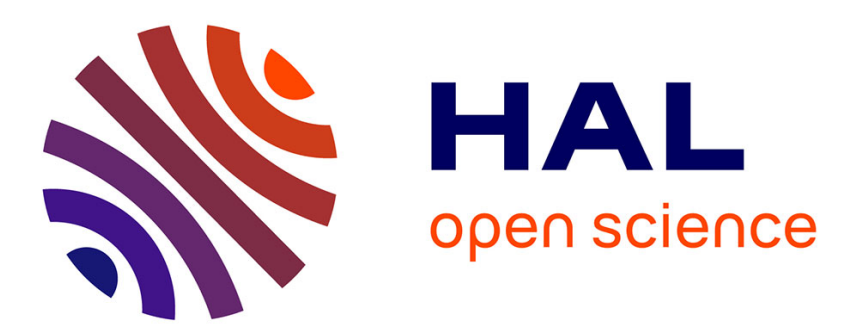

\title{
Functional Product Life-cycle Simulation Model for Cost Estimation in Conceptual Design of Jet Engine Components
}

\author{
Marcus Sandberg, Patrik Boart, Tobias Larsson
}

\section{To cite this version:}

Marcus Sandberg, Patrik Boart, Tobias Larsson. Functional Product Life-cycle Simulation Model for Cost Estimation in Conceptual Design of Jet Engine Components. Concurrent Engineering: Research and Applications, 2005, 13 (4), pp.331-342. 10.1177/1063293X05060136 . hal-00571188

\author{
HAL Id: hal-00571188 \\ https://hal.science/hal-00571188
}

Submitted on 1 Mar 2011

HAL is a multi-disciplinary open access archive for the deposit and dissemination of scientific research documents, whether they are published or not. The documents may come from teaching and research institutions in France or abroad, or from public or private research centers.
L'archive ouverte pluridisciplinaire HAL, est destinée au dépôt et à la diffusion de documents scientifiques de niveau recherche, publiés ou non, émanant des établissements d'enseignement et de recherche français ou étrangers, des laboratoires publics ou privés. 


\title{
Functional Product Life-cycle Simulation Model for Cost Estimation in Conceptual Design of Jet Engine Components
}

\author{
Marcus Sandberg, ${ }^{1, *}$ Patrik Boart ${ }^{1,2}$ and Tobias Larsson ${ }^{1}$ \\ ${ }^{1}$ Polhem Laboratory, Luleå University of Technology, SE-971 87 Luleå, Sweden \\ ${ }^{2}$ Advanced Design Engineering, Volvo Aero Corporation, SE-461 81 Trollhättan, Sweden
}

\begin{abstract}
As functional (total care) products emerge in the jet engine industry, the need for product life-cycle models capable of definition and evaluation of life cycle properties increases, since functional products (FP) includes both hardware and service. Recent life-cycle models are intended for hardware products and mostly handle design and manufacturing knowledge. The aim of this article is to present a design approach that extends the evaluation capabilities beyond classical hardware design and manufacturing evaluation. The focus has been to introduce evaluation of manufacturing and post-manufacturing activities in evaluation of conceptual designs. For this purpose, a model has been proposed to handle the information flow between teams when developing structural jet engine components. A case study, in which the proposed model was used in cooperation with a jet engine component manufacturer, is presented. Aspects concerning design, manufacturing, performance, and maintenance of jet engine flanges were included in the example by means of a knowledge based engineering (KBE)-system coupled to databases and spreadsheets. The model is more suitable than recent work for the development of hardware parts of functional products (HFP), since knowledge from more product development disciplines is included. As the engineer changes the design and directly assesses the life-cycle cost (LCC) and how the changes impact the interface to other jet engine components, more knowledge on the impact of design decisions is available at hand for the engineering designer than without the model.
\end{abstract}

Key Words: knowledge based engineering, product life-cycle, cost, design support systems, conceptual design.

\section{Introduction}

Assessing the life-cycle cost (LCC) of a product during product development is crucial for product success. Hardware product development has worked towards a life-cycle view for several years [1,2]. As functional products (FP) emerge in the jet engine industry [3], the product life-cycle view has to be refined. A FP is a total care product, where the company offers the functionality of the product, compromising hardware and support services, e.g., maintenance, logistics, financing, and training over the life-time of the offer. Today, most jet engine manufacturers are remunerated late in the life-cycles of services on already sold hardware. The manufacturer owns the product while the customer is charged for the operative use of the product. This increases the risk for the manufacturer, since customers are typically guaranteed product availability, and creates new requirements on the manufacturer's PD process because it has to be adapted to FP design, hardware, and service development rather than hardware design alone. It is no

*Author to whom correspondence should be addressed

E-mail: Marcus.Sandberg@1tu.se

Figures 1 and 3-13 appear in color online: http://cer.sagepub.com longer just a design-manufacture-sell issue, but rather a total care issue.

The aero engine business companies join together to share the risk. With a common product to develop, where the different components of the jet engine are divided between the partners, it is necessary to share information and see the effects of each decision. With a FP scenario this is especially important in the early phases. Few applications exist that can support the conceptual design phase in such an enterprise [5]. This is partly because that knowledge about the design requirements and constraints is usually imprecise and incomplete. As the life-cycle of the FP is largely decided upon in the early phases, better tools that can improve the knowledge about how different decisions will affect the product life-cycle are needed.

Figure 1 shows an excerpt of an overview of the system levels in an aircraft engine. Each module consists of a number of components. A change in one component can affect the interface properties in relation to other components. Contracts are used to define what requirements each interface must fulfill. If a change that will affect a requirement in one interface is needed, costly negotiation may ensue. Usually, it is only in the early phases of product development that larger changes are admissible or affordable. 


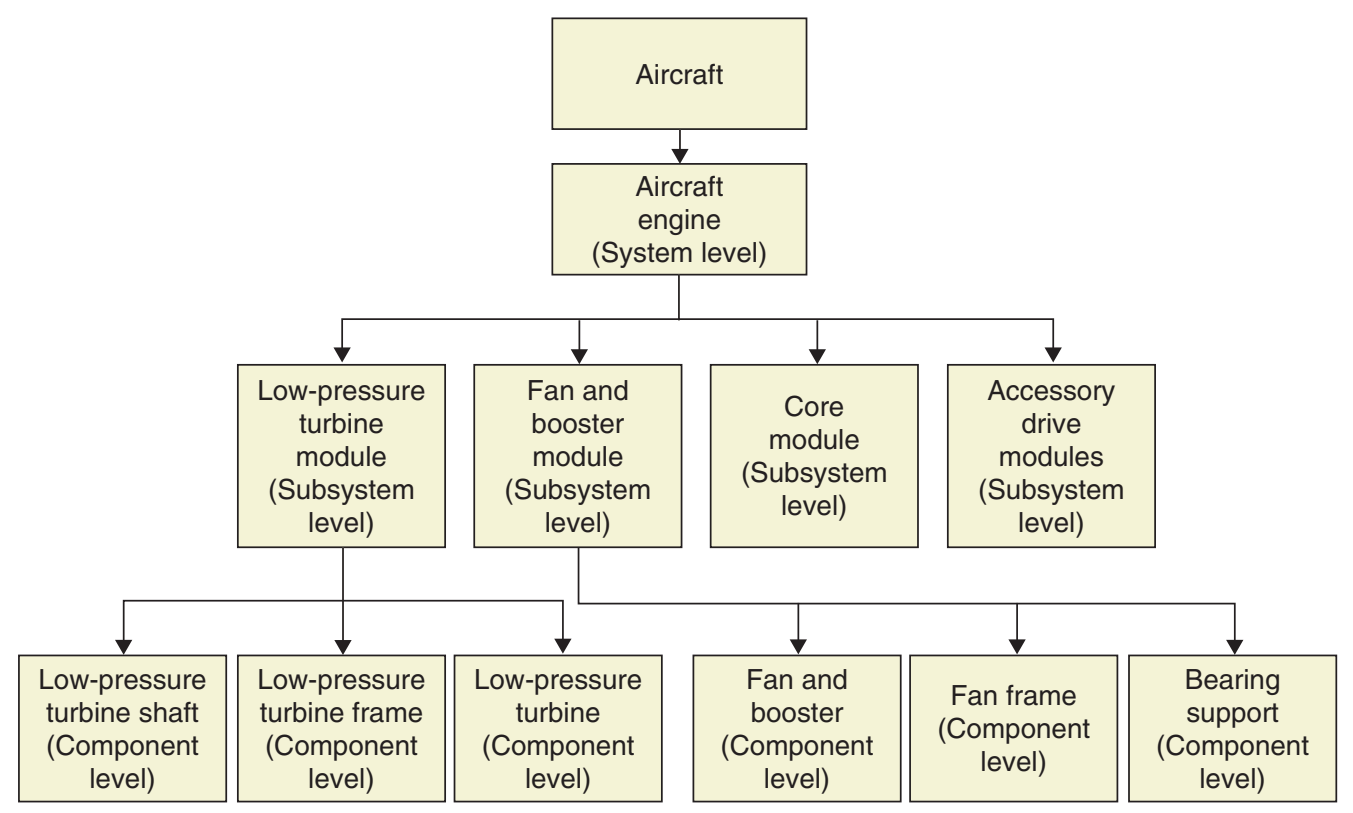

Figure 1. Excerpt from an aircraft system level overview.

Evaluating how changes affect the FP LCC is time consuming. The first obstacle is to manage the contractual agreement efficiently. To make these changes efficient, all partners will need to know how the change will affect the LCC and how they, themselves, will be affected.

Generally, a concurrent engineering (CE) approach is a common means of making a product development process efficient and effective by paralleling and integrating PD processes [1,2]. However, this implies other challanges in managing the product development process as parallel and overlapping activities possibly generate design conflicts. Defining metrics and measures to handle the design conflicts is therefore important [4]. Specifically, it is commonly claimed that one important part of the PD process is the conceptual phase [5], where the boundaries of the product life-cycle are defined and a large part of the product cost to be covered later in the production system is thereby committed [6]. This cost is, however, not often seen until it has occurred, which is why designers may commit more cost than needed [7]. One way of making the cost visible in the conceptual phase is through the life-cycle cost modeling.

A state-of-the-art study regarding product LCC modeling in the early phases of PD has been presented by $\mathrm{Gu} \&$ Asiedu [8], who concluded that most work often concentrates on design and manufacturing activities as recent work often deals with hardware development. More recent work has also focused on hardware products and therefore lacks a wider life-cycle perspective [11,12]. Hence, modeling post-manufacturing activities of the life-cycle is necessary.
The aim of this article is to present a design approach that extends the evaluation capabilities beyond classical hardware design and manufacturing evaluation. The focus has been to introduce evaluation of manufacturing and post-manufacturing activities in evaluation of conceptual designs.

The major contribution from this work is the design support model, which can be used to assess life-cycle cost and create a view of how decisions between a number of design, performance, manufacturing, and maintenance activities affect each other in conceptual design. Designers can jointly assess LCC change due to design changes. It is believed that the design support model is more suitable for the development of hardware parts of functional products (HFP) than recent work because of a wider life-cycle perspective.

The next section summarizes related work regarding the life-cycle cost modeling of mechanical engineering products. Section 3 introduces the proposed model, while Section 4 presents a case study example. Section 5 discusses the usefulness of the design support model. The last section sums up the work and underlines the main conclusions.

\section{Life-cycle Cost Simulation Framework}

Simulating the total product life-cycle is a topic which was highlighted in the beginning of the 1990s through CE presenting a systematic approach for achieving integrated product development. Based on the systematic approach, a vast number of LCC simulation applications have been presented, of which a selection is discussed. 


\subsection{Systematic Approach}

Concurrent engineering (CE) sets the framework for how to integrate product and process organizations [1] and achieve integrated product development [2]. The main theme in CE is the paralleling of engineering processes and activities that earlier on was performed sequentially. Another theme in $\mathrm{CE}$ is the modeling of life-cycle activities using geometry-based, constraintbased and knowledge-based languages and thereby making downstream knowledge (knowledge related to a product development process which is conducted later) available in early design [2], as it is commonly claimed that a majority of the product cost is allocated during the early design stages $[5,6]$. This cost is often not seen until downstream in the PD process in terms of manufacturability, maintainability, possibility to assemble, etc. Cost estimation applications for designers are critical for supporting the early stages of product development $[8,9]$. As the life-cycle models often contain sub-models, for example design, analysis, and process models, life-cycle activities can often be performed in parallel. Parallel activities can, however, lead to design conflicts, such as when output design changes from one activity conflict with output design changes from another. Prasad [4], defines a framework for metrics and measures to support the handling of design conflicts in the design of mechanical components during the whole life-cycle. The measures are divided into categories, e.g., diagnostic and performance measures. Diagnostic measures aim at targeting features of the design that introduce abnormal behavior, while performance measures can be used to determine product performance and include, e.g., 'cost of development'. Prasad [4] also claims that knowledge-based systems can be beneficial in managing metrics and measures, since the product development process can be captured in a model and possibly allow more design iterations per time unit than without the model.

The CE paradigm provides a framework for lifecycle cost simulation. Less attention has however been focused on how to implement $\mathrm{CE}$ in industry. This was noted by Pawar et al. [10], who therefore suggested a conceptual model for implementing and sustaining CE. Many studies have been conducted with an application approach aimed at providing cost-estimation applications for designers [7-9,11-13], several of which are presented and discussed in the next two sections.

\subsection{Application Approach}

$\mathrm{Gu}$ and Asiedu [8] presented a state-of-the-art review of LCC analysis models until 1997, where cost estimation is divided into three approaches: parametric, analogous, and detailed models. It was concluded that the reviewed models were restricted to specific processes, i.e., simple operations or one phase of the life-cycle often the design and manufacturing phase, thereby explaining why it is necessary to develop models that include more parts of the product life-cycle. Dilts and Geiger [9] discuss the gap in timely and precise costing information for designers and present a feature-based modeling system for the costing of new part design, design-to-costing (DTC). This estimation of final product cost is based on existing computer aided design (CAD), accounting, and computer integrated manufacturing databases. A general-purpose conceptual design system for wing structures is presented by Blair and Hartong [11]. Using activity-based costing (ABC), dependency tracking, demand-driven calculations, and run-time object creation, this work aims to connect geometry modeling with cost estimation for the finished product to help the customer to evaluate affordability issues. This work focuses on similar needs as for the HFP, as the customer is partly involved in the development process, changing requirements, and assessing affordability. However, this work concentrates on cost while the product is still at the manufacturer (also similar to [9]) and leaves out service issues. Shehab and Abdalla [12] present a system for concurrent product development to estimate the cost of machined parts using feature-based design coupled to CAD software. Uncertainties in cost estimation are handled by fuzzy logic. The system is claimed to recommend the most economical assembly technique, select the material and manufacturing process based on a number of design and production parameters, and estimate the total product cost, from material cost to assembly cost. This research is useful for manufacturing predictions but needs to be extended to suit HFPs, since, similar to [9] and [11], it estimates cost of activities before the product leaves the manufacturer. Seo et al. [13], present an approach using artificial neural networks to estimate LCC in the conceptual design of consumer products. It is claimed that, in conceptual design, decisions have to be made quickly, even though detailed information is scarce. In contrast to the case of structural jet engine components, which often have similar characteristics from variant to variant, this research is suitable for product development processes that are not fully known or often change.

\subsection{Framework Conclusion}

Apart from the fact that there is a lack of total care product models, most of the earlier work is either on a systematic level or on an application level. The highlevel systematic models are useful as overview but less useful as guidelines for industry implementation. Pawar et al. [10] have also noted this and presented a computerbased initiative for implementing and sustaining concurrent engineering. Application-level work in product life-cycle modeling is concentrated on processes before 
the product leaves the manufacturer and therefore omits important HFP processes such as maintenance, logistics, and training. Therefore, to support HFP development, there is a clear need for models that incorporate lifecycle properties that arise when the product leaves the manufacturer.

\section{Proposed Design Support Model}

This section presents the method decribing how to create a design support application that can simulate LCC in early phases. A justification of the choice of approach is given first, followed by the act of knowledge acquisition and the process of formalizing the acquired knowledge into a computer implementation format. The design support application computer implementation structure is then given, after which the proposed design support model is described.

\subsection{Selection of Approach}

A number of different methods have been used in recent work when creating design support applications for cost estimation, e.g., feature-based modeling [9], KBE [11] and neural networks [13]. Methods used in the reviewed papers in [8] are, among others, expert systems, neural networks, and object-oriented approaches.

In this research, a parametric cost estimation technique is utilized with a knowledge-based engineering approach to couple the geometry definition process to the cost estimation activity. From Stokes [14], knowledge-based engineering is an approach described as:

The use of advanced software techniques to capture and re-use product and process knowledge in an integrated way.

Routine PD activities are suitable for KBE support. Jet engine component design includes such activities. The base of the application presented in this article comprises a commercial $\mathrm{KBE}$ system coupled to a database and a spreadsheet to perform activities not supported by the KBE system.

\subsection{Knowledge Acquisition}

The research case is based on the design of an aircraft engine component. To make an application, its content (knowledge) needs to be acquired. Knowledge acquisition was performed through formal and informal interviews with the industrial partner and by reading company reports. People involved in the acquisition have project-management and engineering positions in the areas of manufacturing, maintenance, and design and are assumed to be qualified to describe the component design process.

An example of acquired knowledge regarding cost estimation is shown below in Equations (1) and (2). Cost is calculated from the time of manufacturing processes, assembly, and material volume.

$$
\text { Cutting Time } \text { surface } X X=\frac{\text { Area }_{\text {surface_} X}}{f_{n, \text { surface_} \_} v_{c, \text { surface_} X}}
$$

where, $f_{n}$ is feed per revolution $(\mathrm{m})$ and $v_{c}$ is cutting speed $(\mathrm{m} / \mathrm{s})$.

Total Bolt Assembly Time $=$ Bolt Assembly Time $\times$ Number of Bolts

\subsection{Knowledge Formalization}

The acquired knowledge was formalized through a company format used for building object-oriented product models. Figure 2 shows an example from the formalized knowledge corresponding to the acquired knowledge in Section 3.2. The table contains five columns, where the first, 'Service Description', defines the name of the class and the second, 'Parent', its parent class. The third column, 'Property', and the fourth column, 'Source', show the property name and whether the property source comes from a rule or a user input $(\mathrm{UD}=$ User Defined). The last column shows how each property is defined (for example, from an equation, from a text file or from a parent class property). During the knowledge formalization process, the design support application structure begins to take shape, see Section 3.4.

\subsection{Design Support Application Structure}

The design support application structure is defined during the knowledge formalization process as the class structure takes shape. The hierarchal class structure is shown in Figure 3. A commercial KBE system was used with a spreadsheet and a database for the implementation. The KBE system enables design of graphical user interfaces used for interaction with the application.

\subsection{Design Support Model}

To make a design change in an interface between components some analysis work is needed to predict the effect of the change. In Figure 4, an AS-IS model is used to explain the process for making a design change. 


\begin{tabular}{|c|c|c|c|c|}
\hline Service Description & Parent & Property & Source & Rules \\
\hline $\begin{array}{l}\text { 1.2.3 Turning Manufacturing } \\
\text { Class }\end{array}$ & 1.2 .1 & $\begin{array}{l}\text { 1. Cutting_time_surface_X } \\
\text { 2. Material } \\
\text { 3. fn_surface_X } \\
\text { 4. vc_surface_X } \\
\end{array}$ & $\begin{array}{l}\text { 1. Rule } \\
\text { 2. UD } \\
\text { 3. Rule } \\
\text { 4. Rule }\end{array}$ & 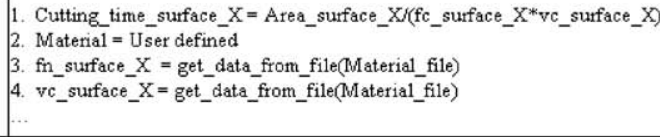 \\
\hline 1.3.2 Assembly Class & 1.3 .1 & $\begin{array}{l}\text { 1. Total_bolt_assembly_time } \\
\text { 2. Bolt_assembly_time } \\
\text { 3. Number_of_bolts } \\
\text {.. }\end{array}$ & $\begin{array}{l}\text { 1. Rule } \\
\text { 2. Rule } \\
\text { 3. Rule } \\
\cdots\end{array}$ & $\begin{array}{l}\text { 1. Total_bolt_assembly_time }=\text { Bolt_assemblt_time } * \text { number_of_bolts } \\
\text { 2. Bolt_assembly_time }=10 \text { ate in table using key: Bolt_type } \\
\text { 3. Number_of_bolts }=1.3 .1 \text { : Number_of_holes }\end{array}$ \\
\hline
\end{tabular}

Figure 2. Excerpt from the formalized knowledge.

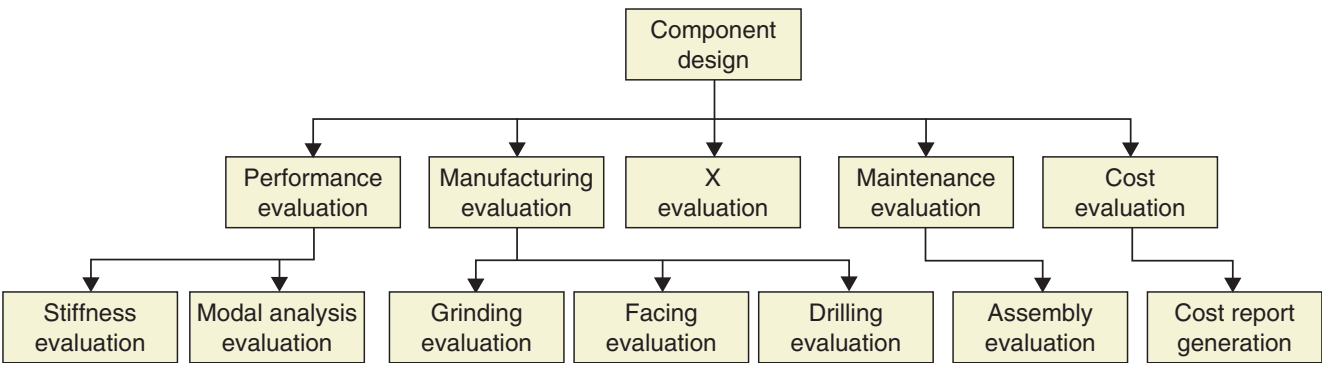

Figure 3. The design support application structure.

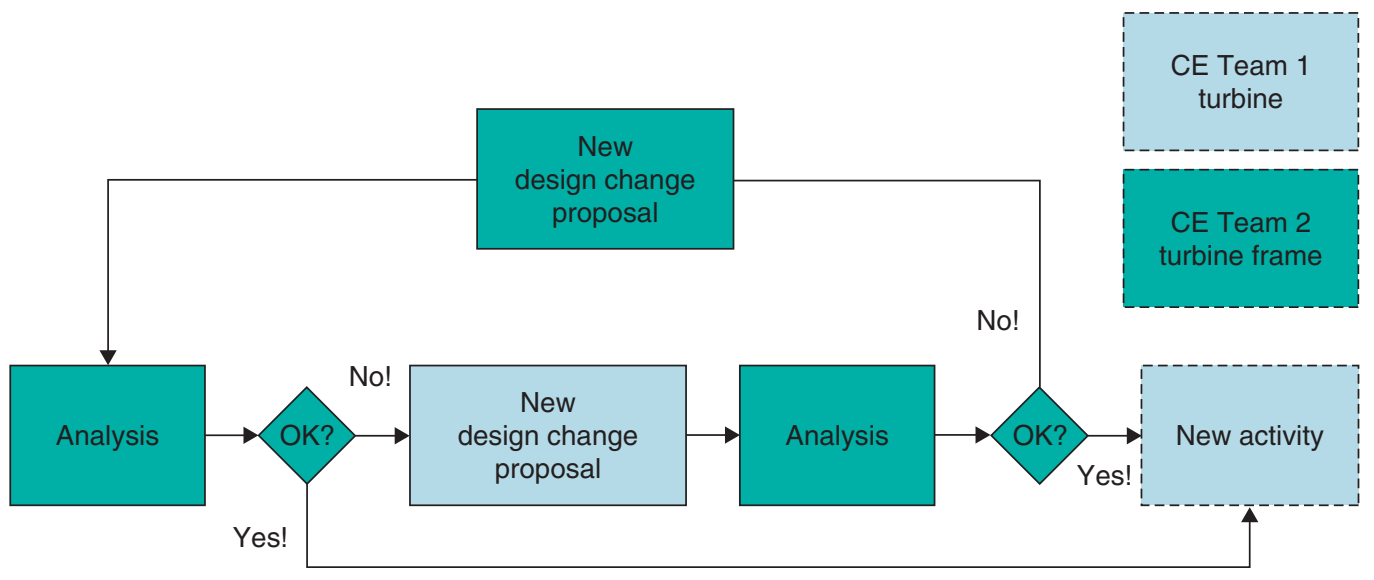

Figure 4. AS-IS model.

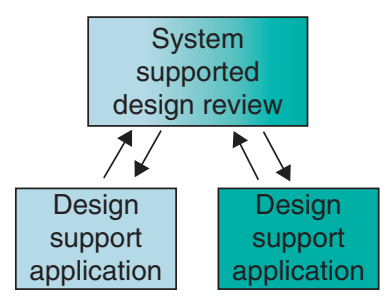

Figure 5. TO-BE: the design support model.

Team 1 has found that they would like to change their interface. This change affects Team 2, who start to evaluate the effect of the change, which might mean repeating all of the analysis work. Depending on the outcome of the analysis, the change will either be accepted or rejected. If possible, a new design change proposal that is close to the suggested change might be suggested.
A TO-BE design support model in Figure 5 is created to improve the efficiency of the AS-IS model. In the TO-BE model, the analysis process is captured in a computerized support system allowing the analysis process to be performed in a fraction of the normal time. This creates an opportunity for Team 1 and Team 2 to negotiate and directly see how the changes will affect each team, see Figure 6.

The teams can now suggest different concepts that can be analyzed directly with the team members discussing the results together. A proposed design change is taken down to the design-support application, which in turn presents the cost.

Figure 7 describes the design support application overview. The design support application consists of a KBE tool that uses a visual basic script to transfer the evaluated manufacturing and maintenance cost 
into a database and spreadsheet to present the costs in diagrams. By changing the definition, all necessary evaluations will automatically be performed and costs will be directly presented in the diagrams.

\section{Case Study Example}

This section presents how the proposed model can be used to support design activities between two concurrent

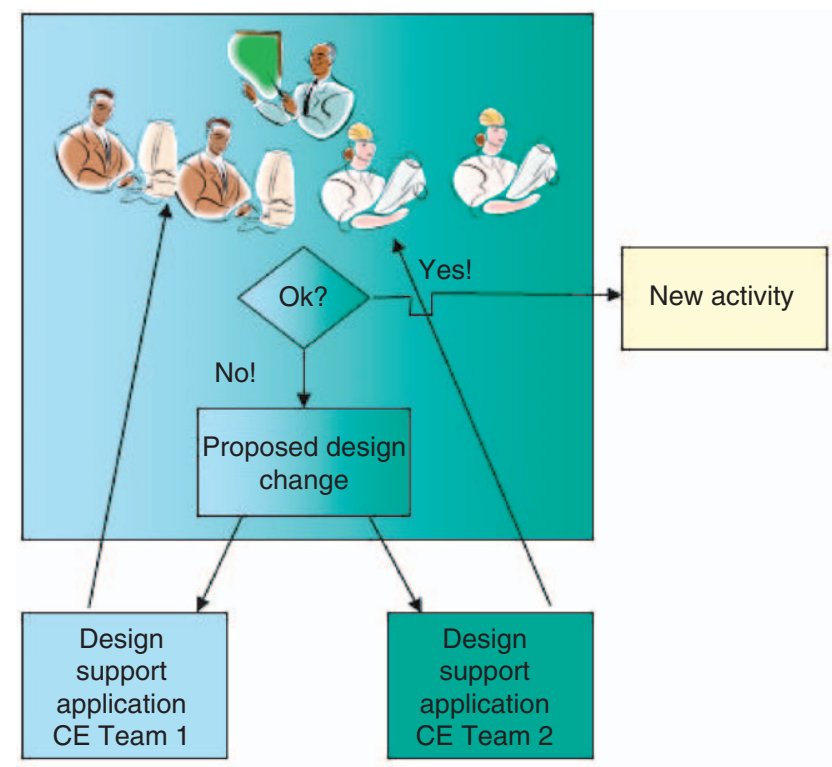

Figure 6. Design review. engineering teams. Modeled activities of the lifecycle described in Section 4.1.2 are believed to be unchanged at HFP development. Firstly, an idealized design process at the partner jet engine manufacturer is presented. Secondly, the usage of the design support model to support the design process, outlined in Figure 5, is described. Finally, the estimation of LCC is presented.

\subsection{Current Design Process}

A concurrent and idealized design process at a jet engine manufacturer was chosen as the LCC modeling case study. This is a hardware design process to be adapted to FP development. This section presents the main characteristics of the chosen design process in terms of activities and corresponding life-cycle measures.

\subsubsection{THE PRODUCT}

The design of jet engine component flanges was chosen due to three major advantages; i.e., the design has few features allowing it to be modeled relatively fast, the flange design affects many aspects of the lifecycle (design, manufacturing, performance, and maintenance) making it suitable for LCC modeling, and the flanges are similar between jet engine component variants, motivating the use of KBE. As most component teams develop flanges, several flanges are developed in parallel.

A sketch of the jet engine component flanges with examples of design requirements is presented

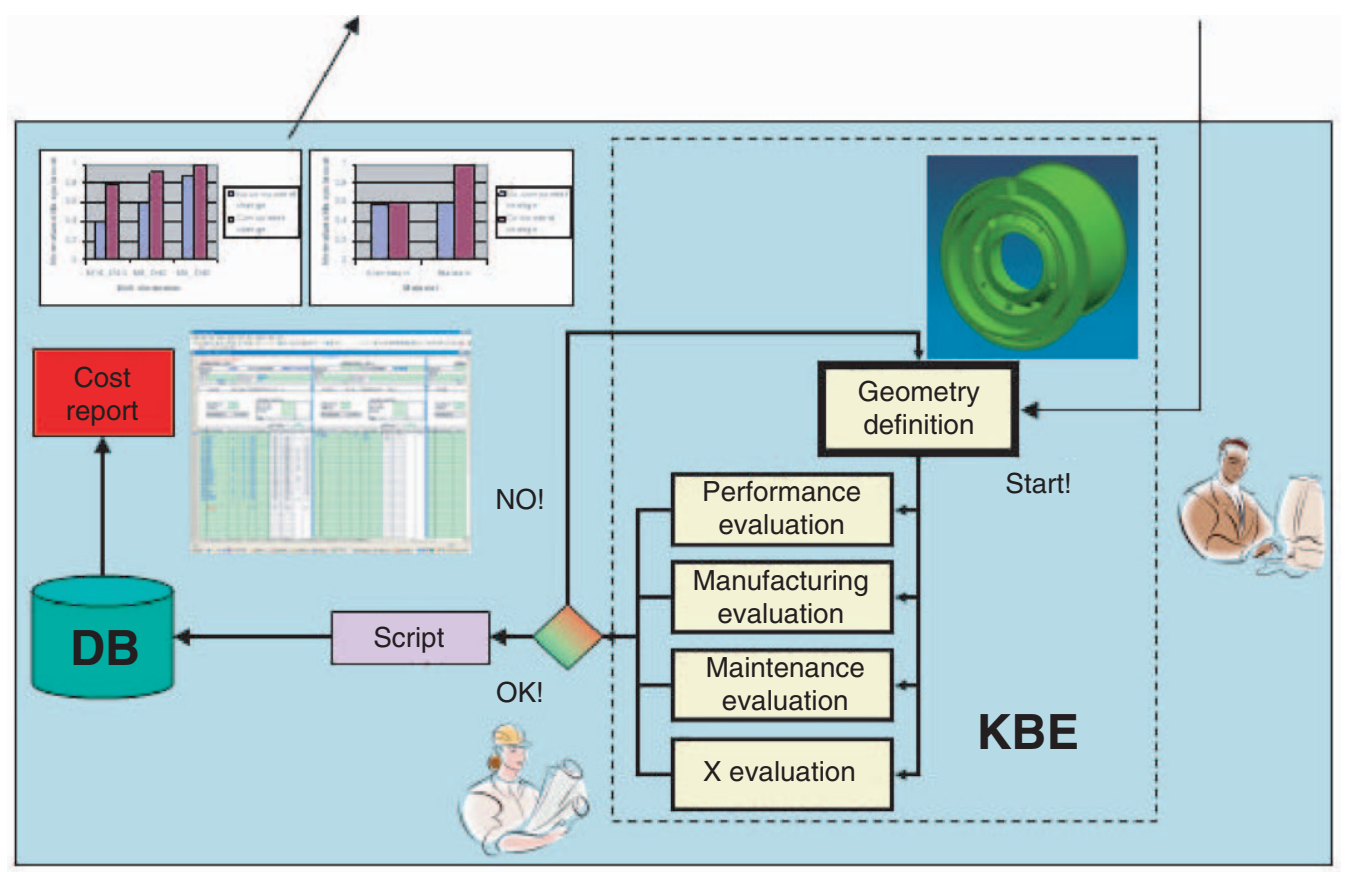

Figure 7. Design support application overview. 
in Figure 8. In general, jet engine components are often rotationally symmetric; hence, the modeled flange is chosen the same way.

\subsubsection{DESIGN STRUCTURE MATRIX}

The process of flange design has been simplified to include the following activities classified into design, performance, manufacturing, and maintenance:

1. Geometry definition

DESIGN

2. Choice of bolt

DESIGN

3. Bolt stress analysis PERFORMANCE

4. Pre-stressing force analysis

5. Flange mantle stress analysis

6. Choice of planar tolerance

7. Choice of surface roughness PERFORMANCE

PERFORMANCE MANUFACTURING

MANUFACTURING

8. Choice of facing method
9. Drilling evaluation

10. Assembly cost evaluation

11. Cost report

The dependency between these activities has been visualized in a design structure matrix, [15] (Figure 9). Here, the DSM is used to visualize the dependency between the activities, though rearranging these activities to an optimal form is beyond the scope of this project. It can be concluded from the DSM, that activities 3-7 and 10 can be performed simultaneously on a sub-component flange level. Activities 8 and 9 can also be performed in parallel on a sub-component flange level. The activities in the DSM are subject to iteration. At any point in any activity it is possible to go back to an earlier activity. As most component teams develop flanges, several flanges are developed in parallel, which is why several DSMs may be performed in parallel.

\subsubsection{EXAMPLE CONFLICT SCENARIOS}

The process of designing the jet engine component flange includes interaction between design, manufacturing, performance, and maintenance, both on a subcomponent flange level and also on a component level where flange design for one component has to be integrated with flange design on the neighboring component. As stated in Section 4.1.2, several activities can be simultaneously performed, possibly leading to design conflicts. These conflicts need measures,

Figure 8. Two rotational symmetric jet engine component flanges.

\begin{tabular}{|l|l|l|l|l|l|l|l|l|l|l|l|}
\hline & 1. & 2. & 3. & 4. & 5. & 6. & 7. & 8. & 9. & 10. & 11. \\
\hline 1. Geometry definition & & $\mathrm{X}$ & & & & & & & & & \\
\hline 2. Choice of bolt & $\mathrm{X}$ & & & & & & & & & & \\
\hline 3. Bolt stress anabysis & & $\mathrm{X}$ & & & & & & & & & \\
\hline $\begin{array}{l}\text { 4. Pre-stressing force } \\
\text { anahysis }\end{array}$ & $\mathrm{X}$ & $\mathrm{X}$ & & & & & & & & & \\
\hline $\begin{array}{l}\text { 5. Flange mantle stress } \\
\text { anabsis }\end{array}$ & $\mathrm{X}$ & & & & & & & & & & \\
\hline $\begin{array}{l}\text { 6. Choice of planar } \\
\text { tolerance }\end{array}$ & $\mathrm{X}$ & & & & & & & & & & \\
\hline $\begin{array}{l}\text { 7. Choice of surface } \\
\text { roughness }\end{array}$ & $\mathrm{X}$ & & & & & & & & & & \\
\hline $\begin{array}{l}\text { 8. Choice of facing } \\
\text { method }\end{array}$ & $\mathrm{X}$ & & & & & $\mathrm{X}$ & $\mathrm{X}$ & & & & \\
\hline $\begin{array}{l}\text { 9. Choice of drilling } \\
\text { tolerance }\end{array}$ & $\mathrm{X}$ & & & & & & $\mathrm{X}$ & & & & \\
\hline 10. Assembly evaluation & $\mathrm{X}$ & $\mathrm{X}$ & & & & & & & & & \\
\hline 11. Cost report & $\mathrm{X}$ & $\mathrm{X}$ & & & & $\mathrm{X}$ & & $\mathrm{X}$ & $\mathrm{X}$ & $\mathrm{X}$ & \\
\hline
\end{tabular}

Figure 9. Design structure matrix for current flange design process. 
as described by Prasad [4], to validate the outcome of each activity. Here are two examples of possible design conflicts which can occur between CE teams, solutions to those conflicts, and clarification of the corresponding measures to solve the conflicts:

1. Conflict scenario: CE Team 1 wants to increase the flange diameter to adjust for a component geometry change. At the design review, CE Team 2 finds that they need to analyze their flange for performance. At the next design review, CE Team 2 has the performance results which indicate that their flange needs to have a larger cross section to remain stiff. This, however, conflicts with the weight requirement, CE Team 2 has on their component and therefore increases the product cost.

Proposed design changes:

- CE Team 1 changes back to component diameter of CE Team 2.

- CE Team 2 changes to a stiffer flange material.

- CE Team 2 violates weight requirement.

Measure: Component diameter, performance.

2. Conflict scenario: CE Team 2 wants to increase the planar tolerance of the interfacing surface between the components to remove leakage problems. At the design review, CE Team 1 finds that they need to calculate the maintenance cost. At the next design review, CE Team 1 has the maintenance cost estimation which suggests that their flange will be too expensive to maintain for the proposed planar tolerance.

Proposed design changes:

- Increase number of bolts instead of planar tolerance.

- CE Team 1 violates maintenance requirement.

Measure: Maintenance cost, leakage (performance).

\subsection{Design Support System}

Section 4.1.3 presented examples of possible design conflicts due to parallel processes. Using the proposed model presented in Section 3, is a possible means of dealing with such conflict scenarios. During the first design review, CE Teams 1 and 2 can try the different proposed design changes by using the system support. For every proposed design change, each team can jointly assess their flanges and then discuss the outcome in terms of performance, manufacturing and maintenance. It is also possible to generate a LCC estimate based on the inputs from the scenario, see Section 4.3 for more details. In Figure 10 a graphical user interface (GUI) is shown, where the flange geometry definition and the performance and weight assessment are controlled.
Figure 11 shows GUI for bolt definition (performance) on the left-hand side and GUI for maintenance evaluation on the right-hand side.

\subsection{Life-cycle Cost Estimation}

The proposed model has been used to approximate LCC in the flange design scenarios. This LCC is then automatically printed into graphs for easier comparison. When developing an HFP, choosing a low-cost hardware that can be changed often is a possibility; this is named 'component change' in Figures 12 and 13. Another possibility is to develop an expensive hardware that does not need to be exchanged during the entire life-cycle; this is denoted 'no component change'. These two scenarios are referred to later on as 'component scenarios'. Figures 12 and 13 shows the LCC due to choice of bolts, material, and surface roughness. The normalized LCC is the sum of the costs for facing and drilling operations, material, bolts, and assembly. If no component is changed, the facing, drilling, and material costs are counted only once, while the maintenance costs are counted 14 times (assumed number of maintenance occasions), e.g., bolt and assembly cost as the assumed policy is to change bolts on every maintenance occasion. At component change all costs are counted 14 times.

The left part of Figure 12 indicates the LCC to be inversely proportional to the bolt dimension, as more bolts are needed for smaller bolt dimensions, generating longer drilling and assembly times and resulting in higher cost. This is the case for both component scenarios, whilst the scenario without any component change generates the largest difference. The right side of Figure 12 shows that the use of aluminum (Al) does not sufficiently reduce the LCC for a no component change to not choose titanium (Ti), whilst for a component change Al is almost half the cost of Ti. The left part of Figure 13 shows that the surface roughness does not significantly affect the LCC. It can, however, be seen in the right part of Figure 13 that the cost of facing is more than doubled for steel when comparing the extremes of surface roughness. It can also be seen that $\mathrm{Ti}$ is considerably more expensive for facing than steel.

\section{Discussion}

Functional products (FP) will require the current hardware development process (i.e., how to develop a HFP; the hardware part of a functional product) to change, because the hardware is developed as a part of a total care product also comprising services. Presently, these requirements are not explicitly defined for the case study process presented here, though it is plausible that many steps of the hardware development 


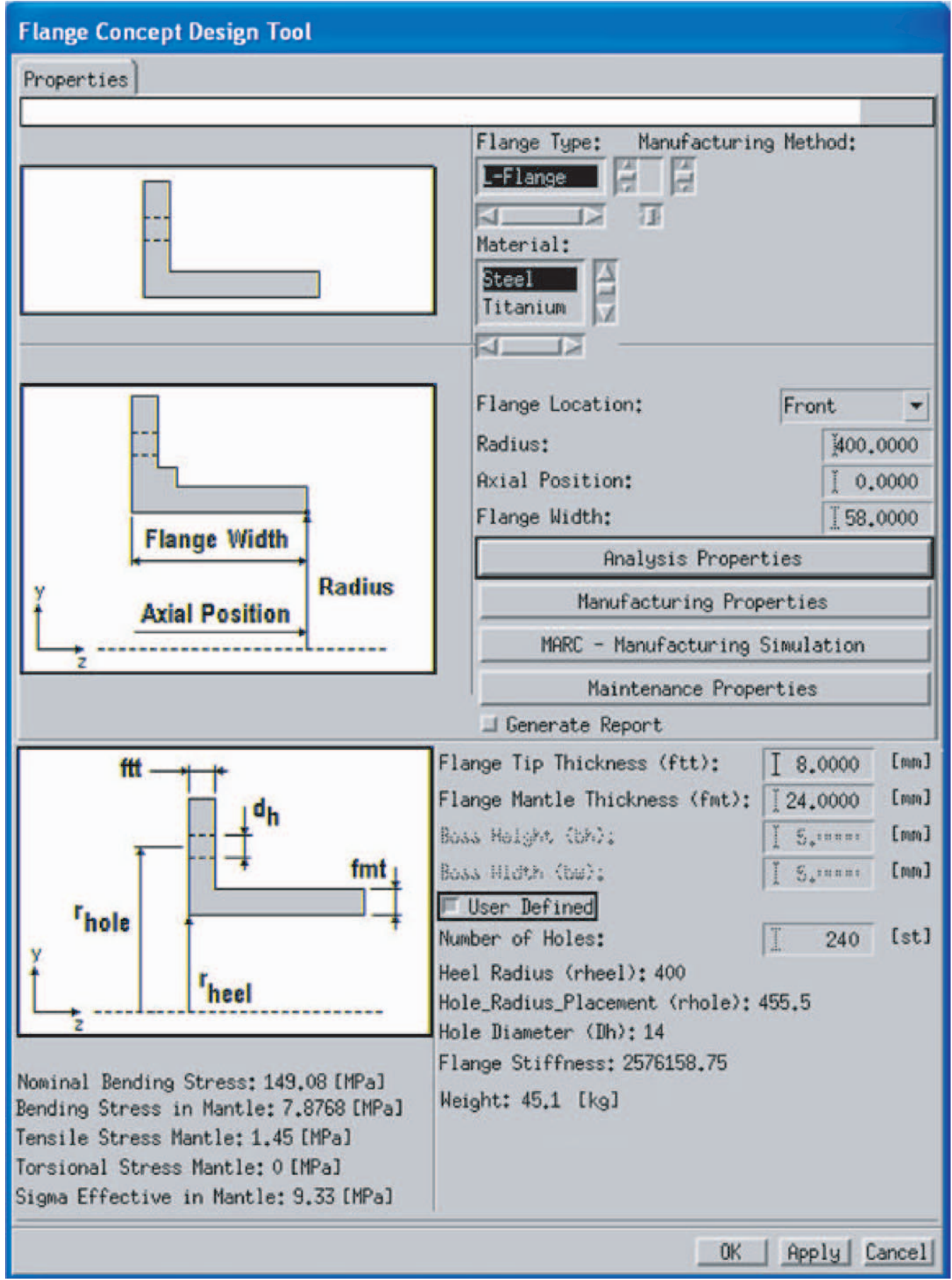

Figure 10. GUI for geometry definition and performance and weight evaluation.

process will still be performed in the current fashion. Examples are stiffness analysis, modal analysis, facing evaluation, and drilling evaluation. This motivates the capture of current design intent.

Since the manufacturer owns an FP, reducing the LCC is important. LCC has traditionally not been used on a more detailed product design stage. By using the design support model, it is possible for the designer to see the effects of design changes on LCC, thereby allowing the designer to choose geometric properties, material, manufacturing, and maintenance operations that give the lowest LCC. This is particularly useful in the early stages of PD because a major part of the product cost is committed there.

By using the design support model it is possible to prevent design conflicts between the modeled disciplines, as the engineers can jointly synthesize and assess the design in terms of manufacturability, maintainability, 


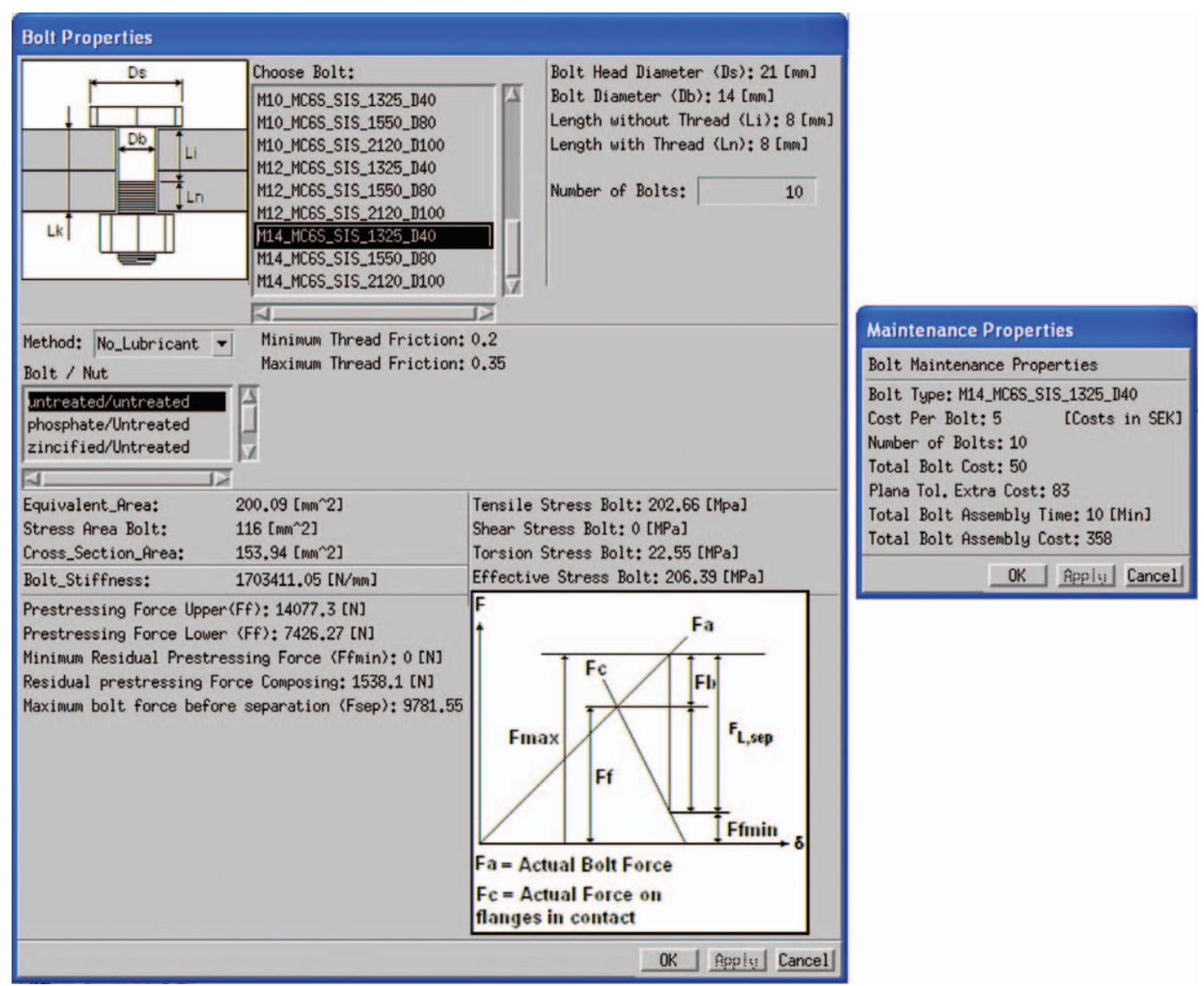

Figure 11. GUI for bolt definition (left-hand side) and maintenance evaluation (right-hand side).
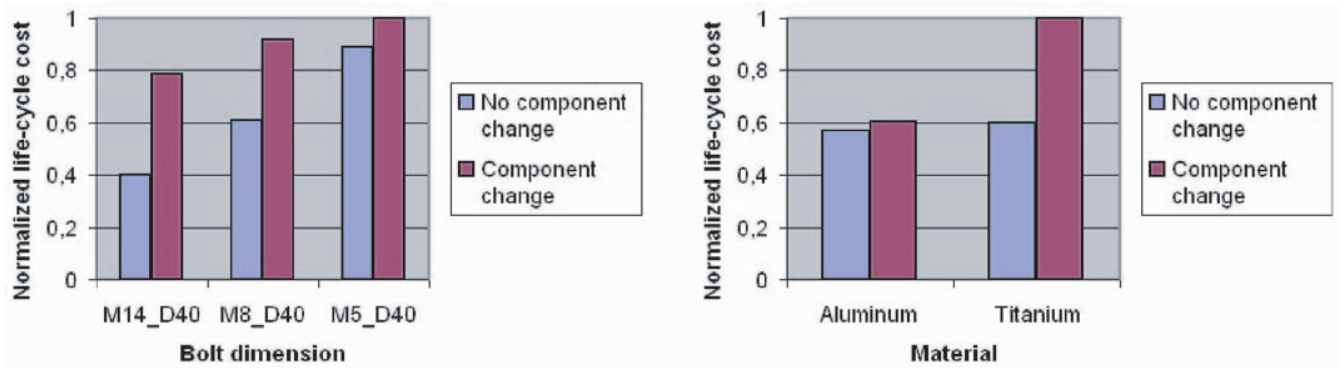

Figure 12. Normalized LCC due to bolt choice (left) and material choice (right).
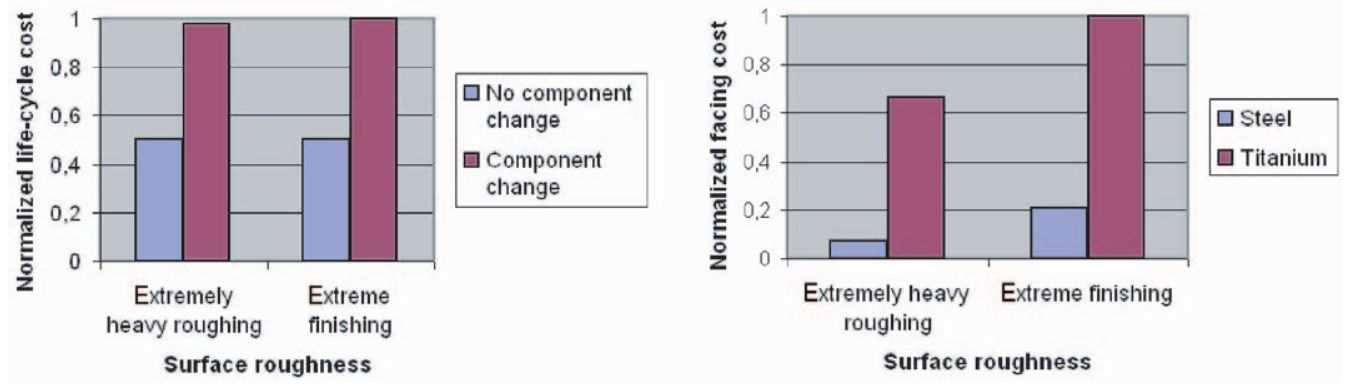

Figure 13. Normalized LCC due to surface roughness choice (left) and normalized facing cost due to material change (right). 
performance, and $\mathrm{x}$-ability. It is also possible to try many what-ifs and therefore optimize the design to more life-cycle aspects. Maintenance is one important service in a FP. As concept designers evaluate maintainability, the design support system is more suitable for FP development than other presented LCC modeling tools.

Many steps of the component design process are automated and may save time in the long term. Quality may also improve due to the avoidance of concepts with poor manufacturability and poor maintainability. It is always tough to measure improvement in product development in large-scale businesses owing to the large number of people involved and the fact that the PD process itself may gradually change. It can only be stated that by using the design support system, the process of defining and evaluating a jet engine component can be speeded up, since the geometry definition process is automated and the evaluation process is governed by rules.

The design support application is built on software used by the industrial partner, which facilitates the process of going from theory to practice in the industry. This design support application shows the principles for LCC assessment from the case-study design process. Extending the application in terms of acquiring further knowledge on the component level is necessary if the application is to be used in industry.

The presented design support model handles activities occuring after the product has left the manufacturer, a feature which is lacking in recent work and is important for HFP design. The time required to construct rule-based models is a common issue, as all rules describing an activity need to be acquired. However, when all rules are acquired, a quality control is gained, as the output follows the rules. A captured process will always be performed according to the captured rules and it will be done each time the process is performed. This allows concepts to be compared on equivalent terms, even if personnel change, as the process for each concept becomes known over time, and it allows repetition whenever needed. Rule-based models are dependent on the simulated process being performed as modeled; otherwise, uncertainties are introduced into the cost estimation. These uncertainties can be handled using, e.g., fuzzy logic. But since jet engine components do not vary much between variants, this is unlikely to happen.

\section{Conclusion}

This article presents a model for life-cycle cost (LCC) prediction in the conceptual development of the hardware part of functional (total care) products. A case example has been developed in collaboration with a jet engine manufacturer. The following conclusions can be drawn from the design support model:

- As the model incorporates activities that will occur after the product has left the factory, it enables consideration of important functional product (FP) scenario issues as design engineers can directly assess LCC during detail design.

- The model can help design-review activities by giving fast LCC feedback on proposed design changes between teams working with interfacing components.

\section{Acknowledgments}

This work has been funded by VINNOVA via TIPS (Tillverkningsindustrins produktframtagning) and NFFP (Nationella flygtekniska forskningsprogrammet). The support of these organizations is hereby gratefully acknowledged. The authors also wish to thank Volvo Aero Corporation for making information available. This information has been altered to protect companyspecific data.

\section{References}

1. Prasad, B. (1996). Concurrent Engineering Fundamentals: Integrated Product and Process Organization, Vol. I, Saddle River, New Jersey: Prentice and Hall.

2. Prasad, B. (1997). Concurrent Engineering Fundamentals: Integrated Product Development, Vol. II, Saddle River, New Jersey: Prentice and Hall.

3. Alonso-Rasgado, T., Thompson, G. and Elfström, B.-O. (2004). The Design of a Functional (Total Care) Product, Journal of Engineering Design, 15(6): 515-540.

4. Prasad, B. (2000). Survey of Life-cycle Measures and Metrics for Concurrent Product and Process Design, Artificial Intelligence for Engineering Design, Analysis and Manufacturing, 14(2): 163-176.

5. Wang, L., Shen, W., Xie, H., Neelamkavil, J. and Pardasani, A. (2002). Collaborative Conceptual Design State of the Art and Future Trends, Computer-Aided Design, 34(13): 981-996.

6. Barton, J., Love, D.M. and Taylor, G.D. (2001). Design Determines $70 \%$ of Cost? A Review of Implications for Design Evaluation, Journal of Engineering Design, 12(1): 47-58.

7. Kuo, T.-C., Huang, S.H. and Zhang, H.-C. (2001). Design for Manufacture and for " $X$ ": Concepts, Applications and Perspectives, Computers and Industrial Engineering, 41(3): 241-260.

8. Gu, P. and Asiedu, Y. (1998). Product Life-cycle Cost Analysis: State of the Art Review, International Journal of Production Research, 36(4): 883-908.

9. Dilts, D.M. and Geiger, T.S. (1996). Automated Design-to-cost: Integrating Costing into the Design Decision, Computer-Aided Design, 28(6/7): 423-438.

10. Pawar, K.S., Haque, B. and Weber, F. (2002). Computer Based Initiatives for Implementing and Sustaining Concurrent Engineering, Concurrent Engineering: Research and Applications, 10(1). 
11. Blair, M. and Hartong, A. (2000). Multidisciplinary Design Tool for Affordability, American Institute of Aeronautics and Astronautics AIAA-2000-1378.

12. Shehab, E.M. and Abdalla, H.S. (2001). Manufacturing Cost Modelling for Concurrent Product Development, Robotics and Computer Integrated Manufacturing, 17(4): 341-353.

13. Seo, K.-K., Park, J.-H., Jang, D.-S. and Wallace, D. (2002). Approximate Estimation of the Product Life-cycle Cost Using Artificial Neural Networks in Conceptual Design, International Journal of Advanced Manufacturing Technology, 19(6): 461-471.

14. Stokes, M. (2001). Managing Engineering Knowledge MOKA: Methodology for Knowledge Based Engineering, ASME Press, ISBN 0-7918-0165-9.

15. Steward, D.V. (1981). Systems Analysis and Management: Structure, Strategy and Design, New York: Petrocelli Books, ISBN 0-894-33106-X.

\section{Marcus Sandberg}

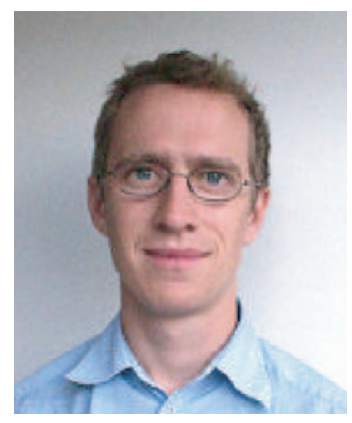

Marcus Sandberg is currently a $\mathrm{PhD}$ student at the Division of Computer Aided Design, Luleå University of Technology. He completed an MSc in Mechanical Engineering at same university in February 2002. His research interests are in the areas of engineering design, knowledge enabled engineering, and design for manufacturing.

\section{Patrik Boart}

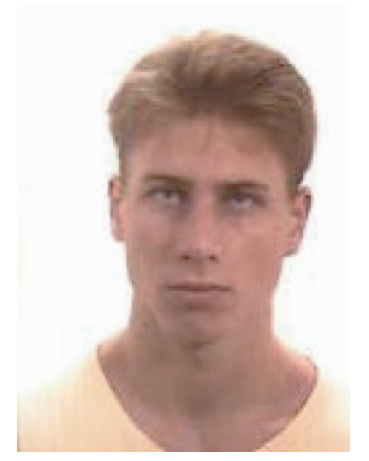

Patrik Boart is a $\mathrm{PhD}$ student at the Division of Computer Aided Design, Luleå University of Technology. He completed an MSc in Mechanical Engineering at same university in May 2002. His research interests are in the areas of engineering design, knowledge enabled engineering, and functional products.

Tobias Larsson

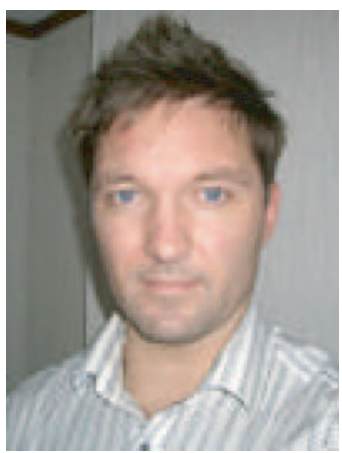

Tobias Larsson is an associate professor at Division of Computer Aided Design, Luleå University of Technology. His research interests are in the areas of engineering design, simulation driven design, and knowledge enabled engineering. $\mathrm{He}$ is also a member of ASME and Design Society. 